\title{
Opposite associations of age-dependent insulin-like growth factor-I standard deviation scores with nutritional state in normal weight and obese subjects
}

\author{
Harald Jörn Schneider ${ }^{1,2}$, Bernhard Saller ${ }^{3}$, Jens Klotsche ${ }^{2}$, Winfried März ${ }^{4}$, Wolfgang Erwa ${ }^{4}$, \\ Hans-Ullrich Wittchen ${ }^{1}$ and Günter Karl Stalla ${ }^{2}$ \\ ${ }^{1}$ Institute of Clinical Psychology and Psychotherapy, Technical University of Dresden, Germany, ${ }^{2}$ Internal Medicine/Endocrinology and Clinical \\ Chemistry, Max Planck Institute of Psychiatry, Kraepelinstr. 10, 80804 Munich, Germany, ${ }^{3}$ Pfizer GmbH, Karlsruhe, Germany and ${ }^{4}$ Institute of \\ Clinical Chemistry, Medical University, Graz, Austria
}

(Correspondence should be addressed to H J Schneider; Email: schneider@mpipsykl.mpg.de)

\begin{abstract}
Objective: Insulin-like growth factor-I (IGF-I) has been suggested to be a prognostic marker for the development of cancer and, more recently, cardiovascular disease. These diseases are closely linked to obesity, but reports of the association of IGF-I with measures of obesity are divergent. In this study, we assessed the association of age-dependent IGF-I standard deviation scores with body mass index (BMI) and intra-abdominal fat accumulation in a large population.

Design: A cross-sectional, epidemiological study.

Methods: IGF-I levels were measured with an automated chemiluminescence assay system in 6282 patients from the DETECT study. Weight, height, and waist and hip circumference were measured according to the written instructions. Standard deviation scores (SDS), correcting IGF-I levels for age, were calculated and were used for further analyses.

Results: An inverse U-shaped association of IGF-I SDS with BMI, waist circumference, and the ratio of waist circumference to height was found. BMI was positively associated with IGF-I SDS in normal weight subjects, and negatively associated in obese subjects. The highest mean IGF-I SDS were seen at a BMI of $22.5-25 \mathrm{~kg} / \mathrm{m}^{2}$ in men $(+0.08)$, and at a BMI of $27.5-30 \mathrm{~kg} / \mathrm{m}^{2}$ in women $(+0.21)$. Multiple linear regression models, controlling for different diseases, medications and risk conditions, revealed a significant negative association of BMI with IGF-I SDS. BMI contributed most to the additional explained variance to the other health conditions.

Conclusions: IGF-I standard deviation scores are decreased in obesity and underweight subjects. These interactions should be taken into account when analyzing the association of IGF-I with diseases and risk conditions.
\end{abstract}

European Journal of Endocrinology 154 699-706

\section{Introduction}

Insulin-like growth factor-I (IGF-I) plays a major role in regulating cell growth and differentiation and is a major mediator of the various effects of growth hormone (GH). In consequence, serum levels of IGF-I are often used to assess the status of the GH axis (1-4) and, in consequence, IGF-I has been established as a useful marker for monitoring GH substitution in GHdeficient states (5) and for monitoring treatment effects in acromegaly (4).

In addition to these well established applications, several recent studies have provided evidence that IGF-I levels are positively associated with the risk for certain malignancies $(6,7)$ and negatively associated with cardiovascular risk factors and diseases $(8-11)$. Although the relationship between IGF-I and cardiovascular disease remains inconclusive, with other studies showing detrimental effects of IGF-I on cardiovascular risk $(12-14)$, these data clearly demonstrate that IGF-I is no longer a marker exclusively used for the diagnosis and follow-up of patients with disorders of $\mathrm{GH}$ secretion, but is of interest in many other diseases such as malignancies and cardiovascular disorders.

Since obesity is often causally involved in the pathogenesis of these diseases, it is crucial to characterize precisely a possible association of IGF-I levels with nutritional status before discussing a causal link 
between IGF-I and various disease states. In conditions of underweight such as anorexia nervosa or cachexia, decreased IGF-I and increased GH levels due to GH insensitivity are found (15-18). Obesity is characterized by blunted GH secretion $(16,19)$ but reports of IGF-I levels in obese subjects are divergent. Some authors have reported decreased levels of IGF-I (20-22), while others have found normal levels (23-25), which could be due to an increased GH sensitivity in obese subjects (25). Negative correlations of IGF-I levels to visceral fat areas, assessed by computed tomography scan $(23,26,27)$ have been reported even in the absence of significant correlations between body mass index (BMI) and IGF-I (23), suggesting that the amount of visceral fat is an important determinant of IGF-I levels.

Since all available studies about the association between obesity and IGF-I levels have been conducted in small populations, the present study aimed to assess this question in a population of more than 6000 subjects participating in the DETECT study, a large multistage cross-sectional study in Germany. To minimize the influence of age, IGF-I levels were measured with an automated immunoassay system, for which recent agedependent reference values in a large cohort of normalweight healthy subjects have been published (29), and were expressed as standard deviation scores (SDS).

\section{Subjects and methods}

\section{Subjects}

The study was approved by the local ethics committee and all patients gave written informed consent. IGF-I was measured in 3723 women and 2559 men, a random sample from the DETECT study, representative of the total DETECT population.

DETECT is a large multistage cross-sectional study of 55518 unselected consecutive patients $(59 \%$ women and $41 \%$ men; over 17 years of age) in 3188 primary care offices in Germany, with a prospective 12-month component in a random subset of 7519 patients, characterized additionally by an extensive standardized laboratory program with focus on cardiovascular (CV) risk assessment. Patients' self-assessments and physicians' assessments of each patient were obtained. Table 1 summarizes the patients' characteristics in detail. Further details are available at http://www.detect-studie.de. The design, methods and baseline characteristics of DETECT, and first prevalence data have been published by Wittchen et al. (30).

\section{Instruments and measurements}

Physicians' diagnoses were classified as definite, possible or not present, and current medication was recorded. In the case of diabetes, type 1 or type 2 was indicated. Laboratory values, obtained in the central
Table 1 Patients characteristics.

\begin{tabular}{lcc}
\hline & $\begin{array}{c}\text { Female }(n=4438) \\
\%\end{array}$ & \begin{tabular}{c} 
Male $\left(\begin{array}{c}n=3081) \\
\%\end{array}\right.$ \\
\hline Sex
\end{tabular} \\
Age (mean/s.D.) & 59.0 & 41.0 \\
BMl (mean/s.D.) & $57.0 / 14.9$ & $58.7 / 13.5$ \\
Diabetes type 2 & $26.7 / 5.3$ & $27.7 / 4.2$ \\
Kidney diseases $^{\mathrm{a}}$ & 17.3 & 27.4 \\
Liver diseases $_{\text {Cancer }}$ & 2.9 & 5.9 \\
CHD $^{\mathrm{b}}$ & 5.7 & 6.7 \\
Hypertension $^{\mathrm{c}}$ & 3.2 & 3.6 \\
Dyslipidemia $^{\mathrm{d}}$ & 9.7 & 20.6 \\
Fibrate intake $^{\text {HRT }}$ & 55.9 & 67.0 \\
HRT $^{\mathrm{e}}$ & 57.8 & 71.9 \\
\hline
\end{tabular}

${ }^{a}$ Clinical diagnosis of type 2 diabetes; ${ }^{b}$ clinical diagnosis of $\mathrm{CHD}$, coronary heart disease; ' systolic blood pressure (SBP) $>=140 \mathrm{mmHg}$ or diastolic blood pressure (DBP) $>=90 \mathrm{mmHg}$ or intake of antihypertensive medication (NHANES criteria); ' ${ }^{2}$ levels above total cholesterol $>240 \mathrm{mg} / \mathrm{dl}$, LDLcholesterol $>160 \mathrm{mg} / \mathrm{dl}$ or $\mathrm{HDL}$ cholesterol $<40 \mathrm{mg} / \mathrm{dl}$; ${ }^{\text {ehormone replace- }}$ ment therapy for women.

laboratory in Graz, were additionally used for the diagnosis of dyslipidemia. Doctors were advised to measure weight, height, blood pressure, and waist and hip circumference according to the manual instructions. Systolic and diastolic blood pressures were measured by indirect cuff sphygmomanometry after several minutes of rest in the sitting position. Waist circumference (WC) was measured with a tape measure midway between the lowest rib and the pelvis; hip circumference $(\mathrm{HC})$ was measured at the widest circumference of the hip. The following anthropometric parameters were calculated: BMI, WC (in cm), $\mathrm{HC}$ (in $\mathrm{cm}$ ), waist-to-hip ratio (WHR) (WC divided by the HC), waist-to-tallness-ratio (WTR) (WC divided by measured height in $\mathrm{cm}$ ).

For the assessment of confounding conditions, physicians' diagnoses were used except for the following: dyslipidemia (levels of total cholesterol $>6.2 \mathrm{mmol} / \mathrm{l}$ $(240 \mathrm{mg} / \mathrm{dl})$, low density lipoprotein-cholesterol $>4.1 \mathrm{mmol} / \mathrm{l}(160 \mathrm{mg} / \mathrm{dl})$ or high density lipoproteincholesterol $<1.0 \mathrm{mmol} / \mathrm{l}(40 \mathrm{mg} / \mathrm{dl}))$ and hypertension (systolic blood pressure (SBP) $\geq 140 \mathrm{mmHg}$ or diastolic blood pressure (DBP) $>=90 \mathrm{mmHg}$ or intake of antihypertensive medication (NHANES criteria)).

\section{IGF-I measurements}

Blood samples were collected and shipped by courier within $24 \mathrm{~h}$ to the central laboratory at the Medical University of Graz (Austria). IGF-I was measured with an automated chemiluminescence system (Nichols Advantage, Bad Vilbel, Germany). The maximal intraand interassay coefficients of variation were $5 \%$ and $7 \%$ respectively. Reagents and secondary standards were used as recommended by the manufacturer. IGF-I levels were transformed to age-dependent IGF-I SDS according to Brabant et al. (29). 


\section{Statistical analyses}

BMI dependent IGF-I SDS means and standard deviations were illustrated with fractional polynomial fit after smoothing the means and standard deviations in each BMI class using the smoothing window $\mathrm{BMI}-1$ to $\mathrm{BMI}+1$. Multiple linear regression models were used to assess the influence of different nutritional parameters on IGF-I SDS, controlling for different diseases and risk conditions. Model fits were tested using the Pregibon link test. To account for the stratified sampling design, we calculated confidence intervals with the Huber-White sandwich method. The difference between the model proposed by Brabant et al. (29) and the model estimated in our sample was tested with a $t$-test, using the normality of regression coefficients. We also used a $t$-test for comparison of the IGF-I SDS levels in different age groups. All statistical analyses were conducted with the software package STATA 8 (Stata Statistical Software: Release 9.0. College Station, TX: Stata Corporation, 2005).

\section{Results}

There were no differences in IGF-I, BMI, or age among those who were fasted and the non-fasted subjects. We estimated the linear regression model used for calculation of the IGF-I SDS proposed by Brabant et al. (29) in our sample. Our model differed significantly $(P<0.001)$ from that of Brabant et al. The IGF-I SDS mean in our sample was $0.08(P<0.001)$ and 0.08 $(P<0.001)$ after exclusion of subjects with a BMI $>30$ and $<18$. Lower IGF-I SDS values $(P<0.001)$ were found in younger $($ mean $=-0.15,18-44$ years) age groups and higher values $(P<0.001)$ in older age groups $($ mean $=0.34,66+$ years $)$. The means of patients aged 45-65 years were not different to zero. Therefore, we additionally adjusted for age in our regression analysis. IGF-I SDS were calculated in different BMI groups with a width of 2.5 starting from $\leq 17.5 \mathrm{~kg} / \mathrm{m}^{2}$ as shown in Table 2 . In the total sample, IGF-I SDS increased with increasing BMI groups up to a BMI of $27.5-30 \mathrm{~kg} / \mathrm{m}^{2}$ in women and

Table 2 IGF-I SDS in BMI, WTR, and WC groups.

\begin{tabular}{|c|c|c|c|c|c|c|c|c|c|c|c|c|}
\hline & \multicolumn{6}{|c|}{ Total group ${ }^{a}$} & \multicolumn{6}{|c|}{$\begin{array}{c}\text { Subjects with diabetes, cancer, kidney, liver } \\
\text { diseases or HRT excluded }\end{array}$} \\
\hline & \multicolumn{3}{|c|}{ Female $(n=3723)$} & \multicolumn{3}{|c|}{ Male $(n=2559)$} & \multicolumn{3}{|c|}{ Female $(n=2377)$} & \multicolumn{3}{|c|}{ Male $(n=1606)$} \\
\hline & $n$ & Mean & S.D. & $n$ & Mean & S.D. & $n$ & Mean & S.D. & $n$ & Mean & S.D. \\
\hline $\mathrm{BMI}<=17.5$ & 17 & $-0.33^{*}$ & 0.49 & 3 & -0.18 & 0.65 & 16 & $-0.36^{*}$ & 0.5 & 2 & -0.43 & 0.69 \\
\hline $17.5<\mathrm{BMI}<=20$ & 195 & $-0.07^{\star}$ & 0.86 & 15 & $-0.67^{\star}$ & 0.76 & 162 & $-0.09^{*}$ & 0.82 & 13 & $-0.70^{\star}$ & 0.82 \\
\hline $20<\mathrm{BMI}<=22.5$ & 593 & $0.06^{*}$ & 0.82 & 136 & $-0.14^{\star}$ & 0.88 & 458 & $0.04^{*}$ & 0.82 & 104 & -0.13 & 0.89 \\
\hline $22.5<\mathrm{BMI}<=25$ & 780 & 0.15 & 0.84 & 531 & 0.08 & 0.93 & 536 & 0.09 & 0.8 & 382 & 0.05 & 0.85 \\
\hline $25<\mathrm{BMI}<=27.5$ & 707 & 0.18 & 0.91 & 719 & -0.01 & 0.89 & 438 & 0.14 & 0.87 & 488 & 0.02 & 0.87 \\
\hline $27.5<\mathrm{BMI}<=30$ & 551 & 0.21 & 0.92 & 539 & $-0.07^{\star}$ & 0.89 & 321 & 0.19 & 0.79 & 316 & -0.07 & 0.86 \\
\hline $30<\mathrm{BMI}<=32.5$ & 390 & 0.13 & 0.86 & 317 & $-0.13^{\star}$ & 0.88 & 189 & 0.11 & 0.82 & 170 & -0.08 & 0.83 \\
\hline $32.5<\mathrm{BMI}<=35$ & 234 & $0.02^{*}$ & 0.81 & 164 & $-0.2^{*}$ & 0.99 & 124 & $-0.04^{\star}$ & 0.82 & 72 & -0.18 & 1.07 \\
\hline $35<\mathrm{BMI}<=37.5$ & 125 & $-0.06^{*}$ & 0.90 & 69 & $-0.34^{\star}$ & 1.05 & 71 & $-0.16^{*}$ & 0.69 & 29 & 0.08 & 1.07 \\
\hline $37.5<\mathrm{BMI}<=40$ & 59 & $-0.24^{\star}$ & 0.81 & 30 & -0.05 & 0.89 & 27 & $-0.17^{\star}$ & 0.73 & 15 & 0.07 & 0.66 \\
\hline $\mathrm{BMI}>40$ & 72 & $-0.5^{\star}$ & 0.77 & 36 & $-0.53^{\star}$ & 1.17 & 35 & $-0.41^{*}$ & 0.69 & 15 & $-0.76^{\star}$ & 0.84 \\
\hline WTR $<=0.25$ & 1 & 1.88 & - & - & - & - & - & - & - & - & - & - \\
\hline $0.25<$ WTR $<=0.35$ & 3 & 0.37 & 0.22 & 1 & -0.74 & - & 3 & $0.37^{*}$ & 0.22 & 1 & -0.74 & - \\
\hline $0.35<$ WTR $<=0.45$ & 523 & $-0.13^{\star}$ & 0.73 & 82 & 0.00 & 0.76 & 438 & $-0.13^{*}$ & 0.74 & 69 & 0.01 & 0.78 \\
\hline $0.45<$ WTR $<=0.55$ & 1404 & 0.15 & 0.90 & 842 & -0.02 & 0.88 & 961 & 0.10 & 0.84 & 649 & -0.03 & 0.85 \\
\hline $0.55<$ WTR $<=0.65$ & 1246 & 0.18 & 0.87 & 1250 & -0.04 & 0.91 & 709 & 0.15 & 0.83 & 729 & -0.03 & 0.88 \\
\hline $0.65<$ WTR $<=0.75$ & 460 & $0.06^{*}$ & 0.89 & 330 & -0.20 & 1.02 & 226 & 0.08 & 0.83 & 137 & -0.07 & 1.00 \\
\hline $0.75<$ WTR $<=0.85$ & 73 & $-0.21^{*}$ & 0.78 & 46 & -0.11 & 1.05 & 34 & -0.30 & $0.69 *$ & 19 & -0.06 & 1.02 \\
\hline $0.85<$ WTR $<=0.95$ & 13 & $-0.40^{*}$ & 0.69 & 6 & $-0.41^{*}$ & 1.57 & 6 & -0.39 & $0.56^{*}$ & 1 & -1.67 & - \\
\hline WTR > 0.95 & - & - & - & 2 & -1.33 & 0.64 & - & - & - & 1 & -0.88 & - \\
\hline $\mathrm{WC}<=50$ & 1 & 1.88 & - & - & - & - & - & - & - & - & - & - \\
\hline $50<W C<=60$ & 17 & -0.04 & 0.65 & 1 & -0.74 & - & 14 & -0.04 & 0.71 & 1 & -0.74 & - \\
\hline $60<\mathrm{WC}<=70$ & 263 & $-0.16^{\star}$ & 0.74 & 18 & $-0.54^{\star}$ & 1.03 & 223 & $-0.15^{\star}$ & 0.75 & 13 & $-0.72^{\star}$ & 1.14 \\
\hline $70<W C<=80$ & 762 & $0.06^{*}$ & 0.82 & 72 & 0.01 & 0.78 & 560 & $0.01^{*}$ & 0.79 & 61 & 0.06 & 0.8 \\
\hline $80<W C<=90$ & 994 & 0.19 & 0.89 & 319 & -0.04 & 0.83 & 666 & 0.17 & 0.83 & 252 & -0.05 & 0.83 \\
\hline $90<\mathrm{WC}<=100$ & 832 & 0.16 & 0.88 & 890 & 0.03 & 0.92 & 480 & 0.12 & 0.83 & 618 & -0.01 & 0.88 \\
\hline $100<\mathrm{WC}<=110$ & 549 & 0.14 & 0.9 & 719 & $-0.07 *$ & 0.88 & 280 & 0.08 & 0.86 & 418 & -0.01 & 0.82 \\
\hline $110<\mathrm{WC}<=120$ & 201 & $0.02^{*}$ & 0.88 & 358 & $-0.18^{\star}$ & 0.97 & 109 & $0.00 *$ & 0.81 & 171 & -0.11 & 1 \\
\hline $120<\mathrm{WC}<=130$ & 76 & $-0.28^{*}$ & 0.79 & 125 & -0.11 & 1.03 & 32 & $-0.22^{*}$ & 0.6 & 52 & 0.00 & 0.99 \\
\hline $130<\mathrm{WC}<=140$ & 22 & $-0.38^{\star}$ & 0.8 & 38 & $-0.41^{\star}$ & 1.19 & 10 & $-0.33^{\star}$ & 0.69 & 12 & -0.24 & 0.79 \\
\hline$W C>140$ & 6 & $-0.54^{\star}$ & 0.77 & 19 & -0.23 & 1.34 & 3 & $-0.96^{*}$ & 0.87 & 8 & -0.22 & 1.29 \\
\hline
\end{tabular}

${ }^{a} n=6282$ valid observations with measured IGF-I and anthropometric parameters.

* Significantly different $(P<0.05)$ from group with highest IGF-I SDS mean (reference group marked in bold), tested by multiple $t$-test. 
$22.5-25 \mathrm{~kg} / \mathrm{m}^{2}$ in men, and then decreased with further BMI increments. The maximum mean IGF-I SDS values were 0.21 and 0.08 in women and men respectively. When subjects with diabetes, cancer, renal or liver diseases or hormone replacement therapy were excluded, the results were very similar, with IGF-I SDS somewhat lower than in the total population. In this subset of 3983 subjects, peak mean IGF-I SDS values were 0.19 in women (BMI $27.5-30 \mathrm{~kg} / \mathrm{m}^{2}$ ) and 0.05 in men $\left(22.5-25 \mathrm{~kg} / \mathrm{m}^{2}\right)$. In men, high mean IGF-I scores of 0.08 and 0.07 were also found in the BMI groups of $35-37.5 \mathrm{~kg} / \mathrm{m}^{2}$ and $37.5-$ $40 \mathrm{~kg} / \mathrm{m}^{2}$, which may be influenced by the small number of subjects included in these groups.

Figure 1 shows the blotted IGF-I SDS in the total sample and after exclusion of subjects with diabetes, cancer, and kidney or liver diseases. Mean values and 1st and 2nd SDS are shown as smoothed lines.

Table 2 also shows the means and standard deviations of IGF-I SDS among groups with different WC and WTR. Again, IGF-I SDS increased in the lower WC and WTR groups up to a maximum at a WC between 80 and $90 \mathrm{~cm}$ and a WTR between 0.55 and 0.65 for females and at a WC between 90 and $100 \mathrm{~cm}$ and a WTR between 0.35 and 0.45 for males, and then decreased with higher WC and WTR values.

To calculate which anthropometric parameter contributed most to explained variance $\left(\mathrm{R}^{2}\right)$ of IGF-I SDS, we carried out linear regression analyses with each nutritional parameter. As several conditions could possibly influence IGF-I SDS, we controlled for cancer, coronary artery disease, diabetes, hypertension, dyslipidemia, liver diseases, renal diseases, age, and intake of fibrates or sex hormone replacement therapy (HRT, in women). The results are shown in Table 3. There was a weak negative association (indicated by a negative $\beta$-S.D.; an increase of one S.D. of the nutritional parameter leads to the indicated increase change of IGF-I SDS) of IGF-I SDS with BMI and other nutritional, anthropometric parameters in both men and women. BMI contributed most to the additional explained variance in the other health conditions.
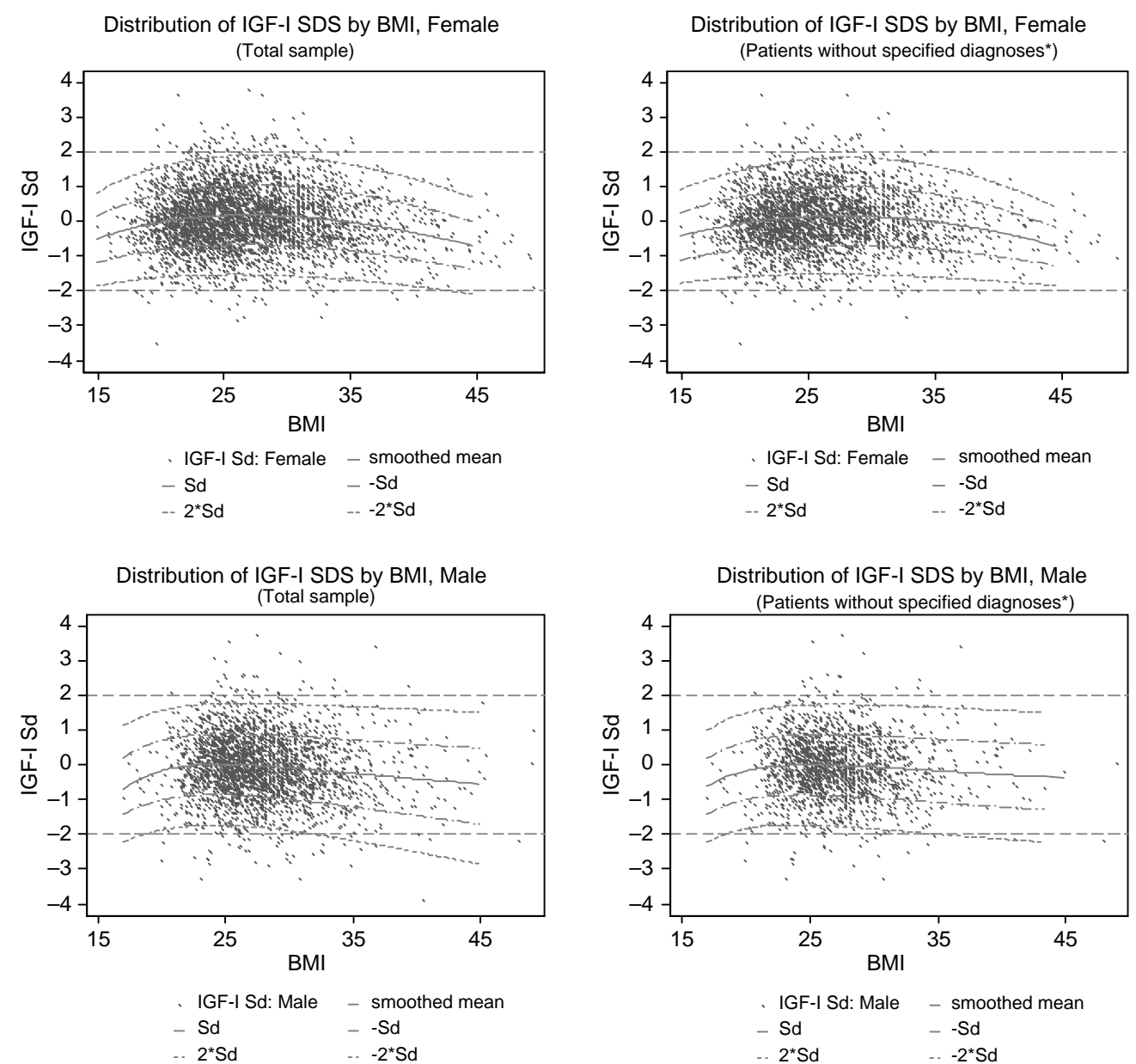

Figure 1 IGF-I SDS blotted over BMI with smoothed lines indicating mean values and 1st and 2nd S.D. (Left panels) Total sample: upper panel, women; lower panel, men. (Right panels) Subjects with diabetes, cancer, kidney or liver diseases, or hormone replacement therapy excluded: upper panel, women; lower panel, men. 
Table 3 IGF-I SDS: additional explained variance of nutritional parameters (model 2) to explained variance by the following conditions: diabetes, liver diseases, kidney diseases, $\mathrm{CAD}$, cancer, hypertension, dyslipidemia, fibrate intake, HRT, and age (model 1). $\mathrm{R}^{2}$ : explained variance. Beta s.D.: standardized regression coefficient. Increase of nutritional parameter for one SD leads to the indicated change of IGF-I SDS.

\begin{tabular}{|c|c|c|c|c|c|c|c|c|c|c|c|c|c|c|c|c|}
\hline & \multirow{3}{*}{$\begin{array}{c}\text { Model } 1^{\mathrm{a}} \\
\mathrm{R}^{2}\end{array}$} & \multicolumn{15}{|c|}{ Model $2^{b}$} \\
\hline & & \multicolumn{3}{|c|}{ BMI } & \multicolumn{3}{|r|}{ WC } & \multicolumn{3}{|r|}{$\mathrm{HC}$} & \multicolumn{3}{|c|}{ WHR } & \multicolumn{3}{|c|}{ WTR } \\
\hline & & $\mathrm{R}^{2}$ & $\begin{array}{l}\text { Beta- } \\
\text { S.D. }\end{array}$ & $\mathrm{Cl}(95 \%)$ & $\mathrm{R}^{2}$ & $\begin{array}{l}\text { Beta- } \\
\text { S.D. }\end{array}$ & $\mathrm{Cl}(95 \%)$ & $\mathrm{R}^{2}$ & $\begin{array}{l}\text { Beta- } \\
\text { S.D. }\end{array}$ & $\mathrm{Cl}(95 \%)$ & $\mathrm{R}^{2}$ & $\begin{array}{c}\text { Beta- } \\
\text { S.D. }\end{array}$ & $\mathrm{Cl}(95 \%)$ & $\mathrm{R}^{2}$ & $\begin{array}{l}\text { Beta- } \\
\text { S.D. }\end{array}$ & $\mathrm{Cl}(95 \%)$ \\
\hline \multicolumn{17}{|l|}{ Total } \\
\hline Female & 8.03 & 8.91 & -0.07 & $-0.098-0.049$ & 8.58 & -0.07 & $-0.093-0.037$ & 8.4 & -0.05 & $-0.072-0.023$ & 8.05 & -0.01 & $-0.042-0.01$ & 8.65 & -0.07 & $-0.092-0.039$ \\
\hline Female, $18-44$ years & 1.32 & 2.01 & -0.06 & $-0.112-0.015$ & 1.6 & -0.05 & $-0.102-0.012$ & 1.7 & -0.05 & $-0.093-0.001$ & 1.29 & 0.00 & $-0.051-0.052$ & 1.68 & $3-0.05$ & $-0.102-0.006$ \\
\hline Female, $45-65$ years & 4.63 & 5.2 & -0.06 & $-0.094-0.021$ & 5.09 & -0.06 & $-0.099-0.016$ & 4.92 & -0.04 & $-0.076-0.004$ & 4.67 & -0.01 & $-0.052-0.023$ & 5.19 & -0.06 & $-0.1-0.02$ \\
\hline Female, $65+$ years & 4.25 & 5.33 & -0.08 & $-0.132-0.037$ & 4.92 & -0.07 & $-0.127-0.021$ & 4.55 & -0.05 & $-0.094-0.003$ & 4.3 & -0.03 & $-0.077-0.022$ & 4.99 & -0.07 & $-0.12-0.022$ \\
\hline Male & 3.26 & 3.95 & -0.08 & $-0.122-0.041$ & 3.68 & -0.07 & $-0.11-0.022$ & 3.41 & -0.04 & $-0.079-0.007$ & 3.57 & -0.06 & $-0.104-0.017$ & 3.86 & -0.08 & $-0.124-0.037$ \\
\hline Male, $18-44$ years & 4.41 & 4.43 & -0.01 & $-0.11-0.082$ & 5.13 & -0.09 & $-0.178-0.006$ & 4.52 & 0.00 & $-0.083-0.09$ & 5.67 & -0.09 & $-0.15-0.031$ & 4.97 & -0.08 & $-0.175-0.017$ \\
\hline Male, $45-65$ years & 2.79 & 3.81 & -0.10 & $-0.149-0.041$ & 3.16 & -0.06 & $-0.123-0.002$ & 3.02 & -0.05 & $-0.112-0.017$ & 2.97 & -0.05 & $-0.122-0.022$ & 3.54 & -0.09 & $-0.149-0.025$ \\
\hline \multirow{2}{*}{\multicolumn{17}{|c|}{. }} \\
\hline & & & & & & & & & & & & & & & & \\
\hline Female & 9.43 & 9.61 & 0.03 & $-0.003-0.066$ & 9.48 & 0.02 & $-0.024-0.064$ & 9.59 & 0.03 & $-0.007-0.067$ & 9.45 & -0.01 & $-0.045-0.032$ & 9.47 & 0.02 & $-0.026-0.056$ \\
\hline Female, & 1.21 & 1.3 & 0.02 & $-0.037-0.079$ & 1.22 & 0.01 & $-0.07-0.089$ & 1.19 & 0.00 & $-0.064-0.074$ & 1.19 & 0.01 & $-0.063-0.075$ & 1.21 & 0.00 & $-0.074-0.079$ \\
\hline Fema & 6.42 & 6.47 & 0.02 & $-0.039-0.071$ & 6.47 & 0.02 & $-0.047-0.086$ & 6.65 & 0.03 & $-0.018-0.087$ & 6.43 & -0.01 & $-0.061-0.046$ & 6.43 & $3 \quad 0.01$ & $-0.054-0.07$ \\
\hline Female & 9.19 & 10.62 & 0.09 & $0.019-0.169$ & 9.2 & -0.01 & $-0.099-0.083$ & 9.75 & 0.06 & $-0.02-0.142$ & 9.71 & -0.06 & $-0.141-0.028$ & 9.2 & 0.01 & $-0.074-0.089$ \\
\hline Male & 3.66 & 4.54 & 0.10 & $0.024-0.181$ & 3.7 & -0.02 & $-0.102-0.064$ & 4 & 0.04 & $-0.018-0.107$ & 4.17 & -0.07 & $-0.151-0.005$ & 3.9 & -0.05 & $-0.133-0.031$ \\
\hline Male, $18-44$ years & 6.57 & 10.01 & 0.21 & $0.048-0.375$ & 6.87 & -0.06 & $-0.211-0.091$ & 7.69 & 0.08 & $-0.04-0.195$ & 8.37 & -0.11 & $-0.215-0.002$ & 7.44 & $4-0.11$ & $-0.271-0.057$ \\
\hline Male, $45-65$ years & 4.22 & 4.38 & 0.04 & $-0.072-0.158$ & 4.24 & 0.02 & $-0.13-0.165$ & 4.41 & 0.04 & $-0.084-0.171$ & 4.27 & -0.03 & $-0.185-0.128$ & 4.35 & $5-0.04$ & $-0.177-0.097$ \\
\hline Male, & 10.31 & 11.16 & 0.10 & $-0.041-0.255$ & 10.31 & 0.00 & $-0.132-0.141$ & 10.55 & 0.04 & $-0.05-0.126$ & 10.49 & -0.05 & $-0.182-0.085$ & 10.31 & $1 \quad 0.00$ & $-0.133-0.132$ \\
\hline \multicolumn{17}{|l|}{$25<\mathrm{BMI}<=30$} \\
\hline Female & 9.16 & 9.16 & -0.01 & $-0.049-0.038$ & 9.17 & -0.01 & $-0.061-0.041$ & 9.08 & 0.00 & $-0.043-0.047$ & 9.08 & -0.01 & $-0.052-0.04$ & 9.24 & $4-0.02$ & $-0.069-0.025$ \\
\hline Female, & 10.3 & 11.54 & 0.01 & $-0.021-0.214$ & 11.55 & 0.11 & $-0.035-0.247$ & 12.76 & 0.14 & $0.02-0.251$ & 10.36 & -0.02 & $-0.136-0.098$ & 11.23 & $\begin{array}{l}3 \quad 0.083 \\
3\end{array}$ & $3-0.044-0.21$ \\
\hline Female, $45-65$ years & 4.87 & 5.01 & -0.02 & $-0.094-0.036$ & 5.12 & -0.04 & $-0.125-0.037$ & 4.87 & -0.00 & $-0.063-0.062$ & 4.97 & -0.02 & $-0.089-0.042$ & 5.31 & $1-0.05$ & $-0.127-0.023$ \\
\hline Female, $65+$ years & 5.58 & 5.58 & -0.00 & $-0.069-0.063$ & 5.58 & 0.00 & $-0.068-0.068$ & 5.66 & -0.02 & $-0.098-0.048$ & 5.66 & 0.03 & $-0.045-0.103$ & 5.65 & $5-0.02$ & $-0.08-0.045$ \\
\hline Male & 3.7 & 3.71 & 0.01 & $-0.038-0.055$ & 3.72 & 0.01 & $-0.043-0.071$ & 3.7 & 0.02 & $-0.037-0.069$ & 3.67 & -0.01 & $-0.072-0.053$ & 3.7 & -0.00 & $-0.06-0.057$ \\
\hline Male, $18-$ & 3.09 & 3.34 & 0.04 & $-0.064-0.136$ & 3.16 & -0.02 & $-0.122-0.082$ & 3.43 & -0.04 & $-0.139-0.068$ & 3.26 & 0.02 & $-0.12-0.152$ & 3.21 & $1-0.03$ & $\begin{array}{ll}-0.14 & -0.087\end{array}$ \\
\hline Male, & 1.06 & 1.07 & -0.01 & $-0.076-0.061$ & 1.12 & 0.02 & $-0.066-0.109$ & 1.15 & 0.03 & $-0.058-0.11$ & 1.08 & -0.01 & $-0.114-0.087$ & 1.07 & $7 \quad 0.00$ & $-0.088-0.096$ \\
\hline Male, $65+$ years & 5.74 & 5.74 & 0.01 & $-0.077-0.087$ & 5.8 & 0.03 & $-0.08-0.133$ & 5.83 & 0.03 & $-0.061-0.115$ & 5.76 & -0.02 & $-0.118-0.087$ & 5.74 & $4 \quad 0.00$ & $-0.1-0.102$ \\
\hline \multicolumn{17}{|l|}{$\mathrm{BMI}>30$} \\
\hline Female & 7.21 & 9.71 & -0.13 & $-0.179-0.073$ & 8.79 & -0.11 & $-0.159-0.053$ & 8.37 & -0.08 & $-0.131-0.029$ & 7.29 & -0.02 & $-0.072-0.028$ & 8.63 & $3-0.09$ & $-0.14-0$ \\
\hline $8-44$ years & 7.5 & 14.77 & -0.18 & $-0.284-0.08$ & 10.2 & -0.12 & $-0.247-0.001$ & 12.86 & -0.14 & $-0.236-0.046$ & 7.88 & 0.04 & $-0.076-0.152$ & 9.7 & -0.10 & $-0.224-0.02$ \\
\hline-65 years & 5.47 & 7.16 & -0.10 & $-0.174-0.02$ & 6.84 & -0.10 & $-0.183-0.018$ & 7.12 & -0.10 & $-0.175-0.023$ & 5.47 & 0.00 & $-0.079-0.082$ & 6.78 & $8-0.09$ & $-0.165-0.015$ \\
\hline Female, $65+$ years & 6.8 & 8.67 & -0.14 & $-0.236-0.034$ & 7.55 & -0.08 & $-0.165-0.011$ & 6.81 & 0.01 & $-0.074-0.088$ & 7.8 & -0.09 & $-0.164-0.006$ & 7.5 & -0.07 & $-0.147-0.014$ \\
\hline Male & 6.75 & 7.19 & -0.06 & $-0.127-0.016$ & 6.82 & -0.02 & $-0.105-0.056$ & 6.77 & -0.01 & $-0.096-0.076$ & 6.9 & -0.04 & $-0.125-0.045$ & 6.85 & $5-0.03$ & $-0.102-0.046$ \\
\hline Male, & 19.83 & 19.86 & 0.02 & $-0.174-0.209$ & 21.07 & -0.11 & $-0.315-0.088$ & 21.63 & 0.11 & $-0.075-0.29$ & 26.02 & -0.17 & $-0.277-0.065$ & 19.83 & $3-0.00$ & $-0.208-0.204$ \\
\hline Male, $45-65$ years & 8.99 & 9.29 & -0.04 & $-0.126-0.044$ & 8.99 & 0.00 & $-0.096-0.106$ & 9.32 & -0.01 & $-0.13-0.113$ & 9.33 & 0.02 & $-0.11-0.14$ & 9.09 & $9-0.03$ & $-0.118-0.067$ \\
\hline Male, $65+$ years & 4.99 & 6.09 & -0.11 & $-0.266-0.054$ & 5.08 & -0.03 & $-0.203-0.145$ & 5.97 & -0.01 & $-0.261-0.074$ & 5.58 & 0.10 & $-0.17-0.364$ & 5.05 & $5-0.02$ & $-0.171-0.128$ \\
\hline
\end{tabular}

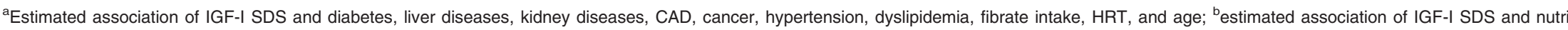
tional parameters, diabetes, liver diseases, kidney diseases, CAD, cancer, hypertension, dyslipidemia, fibrate intake, HRT, and age.

$\mathrm{Cl}$, confidence intervals; CAD, coronary artery disease; HRT, hormone replacement therapy. 
When analyzing subgroups with normal and underweight $\quad\left(\mathrm{BMI} \leq 25 \mathrm{~kg} / \mathrm{m}^{2}\right)$, overweight $\quad(\mathrm{BMI}$ $\left.25-30 \mathrm{~kg} / \mathrm{m}^{2}\right)$, and obese subjects $\left(\mathrm{BMI}>30 \mathrm{~kg} / \mathrm{m}^{2}\right)$, we found diverging results. In normal and underweight subjects we found a positive association between IGF-I SDS and BMI in men, but not in women. Subgroup analysis revealed that this effect was most pronounced in men aged 18-44 years, but it was not significant in men of other age groups, whereas a significant positive association was found in women aged 65 years or older, but not in women of other age groups. There were no significant associations between IGF-I and BMI in overweight individuals. Obese women showed a marked negative correlation that was most pronounced in women aged $18-44$ years. In obese men, BMI was not significantly associated with IGF-I SDS but in the young age group, WHR was significantly negatively associated with IGF-I SDS. In most age subgroups, BMI added most to the explained variance compared with other anthropometric parameters. Only in men aged 18-44 years did the WHR prove to have the strongest association with IGF-I SDS.

\section{Discussion}

To our knowledge, this is the largest study to date assessing the association of IGF-I with nutritional status. In addition, age-dependent IGF-I SDS calculated from the largest published reference sample for IGF-I measurement (29) were used instead of IGF-I levels to analyze associations between IGF-I and various nutritional parameters. By this approach, the confounding effects of the age-dependent decline in IGF-I levels could be excluded. The IGF-I SDS mean in our sample was slightly higher than zero and there was a less steep age-related decline than in Brabant et al. (29). The reason for these differences is unclear. Possibly, differences in morbidities might have played a role. Due to this difference, we additionally adjusted for age in our regression analyses.

Our study clearly established opposite associations of nutritional parameters with IGF-I SDS in normal weight and obese subjects.

It is known that IGF-I levels are decreased in underweight individuals $(15-18)$ and this has been attributed to $\mathrm{GH}$ resistance. The present data extend this observation by showing a continuous increase in IGF-I SDS throughout the normal weight range in both sexes and even further in women. In men with a BMI $\leq 25 \mathrm{~kg} / \mathrm{m}^{2}$, we also found a positive correlation after controlling for possibly confounding health conditions and medications. This observation might indicate that GH sensitivity is not only reduced in severe underweight states, but also may steadily increase within the normal BMI range.

In obese subjects, on the other hand, mean IGF-I SDS decreased with BMI. This confirms the results of some
(20-22) but not all (23-25) previous studies. In our subgroup of obese subjects, an increase of one S.D. of BMI led to a mean decrease of 0.13 and 0.06 IGF-I SDS in women and men respectively. In the literature, a more pronounced impairment of $\mathrm{GH}$ secretion in obesity is described, with a reduction of $\mathrm{GH}$ production to a quarter of that in normal weight subjects (30). Based on these results on $\mathrm{GH}$ secretion in obesity, our results suggest that the reduction in $\mathrm{GH}$ secretion is only partially translated into reduced IGF-I secretion. The reason for this is unclear, but again, an increase in GH sensitivity has been discussed (25). In a population-based study with 400 subjects, a negative correlation of IGF-I with BMI was found that disappeared after adjustment for age (26). We found significant effects of BMI, even after adjustment for age and other health conditions. Possibly, the larger sample number of our study has revealed these associations.

BMI adds about $1 \%$ to the explained variance of IGF-I SDS in the total population and up to $7 \%$ in obese subgroups. Overall, different health conditions only render about $3-8 \%$ of explained variance in the total group and up to $20 \%$ in obese subgroups. These results show that a major part of IGF-I SDS variance still needs to be explained by other factors not assessed in this study, such as genetics or others.

In some studies, a strong negative correlation of visceral fat mass with IGF-I has been found indicating that visceral fat rather than overall body mass determines IGF-I levels $(27,28)$. We have studied several anthropometric indicators of visceral fat accumulation including the WC and the WTR, which have been shown to correlate with intra-abdominal fat (32). Surprisingly, it was the BMI rather than these parameters that added most to explained variance of IGF-I SDS in our total population. However, in the subgroup of young men, the WHR had a better association with IGF-I than with BMI. Since in the study of Kunitomi et al. (28), younger and middle-aged obese men were also investigated, differences between patient populations might be one important explanation for the differences between earlier reports and our study. Moreover, an age-dependent decline in IGF-I, excluded by our approach to the analysis of IGF-I SDS, might have further confounded the findings of previous studies.

The influence of BMI on IGF-I levels is of considerable relevance for studies investigating the association between IGF-I and various disease states. So far, only a few of these studies have adjusted their IGF-I values to BMI. Laughlin et al. (11) have, in a prospective study, investigated the association between IGF-I and cardiovascular risk in a large cohort of older adults from the Rancho Bernardo Study. They found a significant increase in both cardiovascular and all-cause mortality for every unadjusted IGF-I decrease of $40 \mu \mathrm{g} / \mathrm{l}$ (1 SD), which was still significant after adjusting for age. However, when adjusted for age, sex, BMI and prevalent disease, the difference was no longer significant. 
In conclusion, our results indicate that BMI is a slightly better predictor of IGF-I than other anthropometric indicators of nutritional state, and they provide data on the magnitude of this influence in relation to age, BMI and sex. There are opposite associations of BMI to IGF-I SDS in normal weight and in obese individuals. The associations are particularly strong in obese subjects and, in addition, there are sex differences in some subgroups. The data stress the importance of clearly defining subject populations when analyzing the associations of hormonal parameters with nutrition and body composition. These interactions must be taken into account when studying the associations of IGF-I and health conditions that are related to obesity, such as cardiovascular diseases or cancer. Moreover, IGF-I is used to monitor therapy in acromegaly (4) and GH deficiency $(1,3,33)$. The association of BMI with IGF-I should be taken into account when titrating therapy in these patients and, possibly, age- and BMIdependent reference values should be considered in the future.

\section{Acknowledgements}

DETECT (Diabetes Cardiovascular Risk-Evaluation: Targets and Essential Data for Commitment of Treatment) is a cross-sectional and prospective, longitudinal, nationwide clinical epidemiological study. DETECT is supported by an unrestricted educational grant from Pfizer GmbH, Karlsruhe, Germany. Principal investigator: Prof. Dr H-U Wittchen. Staff members: Dr H Glaesmer, E Katze, J Klotsche, A Bayer, A Neumann. Steering Committee: Prof. Dr H Lehnert (Magdeburg), Prof. Dr G K Stalla (München), Prof. Dr M A Zeiher (Frankfurt). Advisory board: Prof. Dr W März (Graz), Prof. Dr S Silber (München), Prof. Dr U Koch (Hamburg), Dr D Pittrow (München/Dresden).

\section{References}

1 Consensus Guidelines for the Diagnosis and Treatment of Adults with Growth Hormone Deficiency, Summary statement of the Growth Hormone Research Society Workshop on Adult Growth Hormone Deficiency. Journal of Clinical Endocrinology and Metabolism $1998 \mathbf{8 3} 379-381$.

2 Hilding A, Hall K, Wivall-Helleryd IL, Saaf M, Melin AL \& Thoren M. Serum levels of insulin-like growth factor I in 152 patients with growth hormone deficiency, aged 19-82 years, in relation to those in healthy subjects. Journal of Clinical Endocrinology and Metabolism $1999 \mathbf{8 4} 2013-2019$.

3 Consensus Guidelines for the Diagnosis and Treatment of Growth Hormone (GH) Deficiency in Childhood and Adolescence, Summary statement of the GH Research Society. Journal of Clinical Endocrinology and Metabolism 200085 3990-3993.

4 Peacey SR \& Shalet SM. Insulin-like growth factor I measurement in diagnosis and management of acromegaly. Annals of Clinical Biochemistry 200138 297-303.

5 Drake WM, Howell SJ, Monson JP \& Shalet SM. Optimizing GH therapy in adults and children. Endocrine Reviews 200122 $425-450$.
6 Chan JM, Stampfer MJ, Giovannucci E, Gann PH, Ma J, Wilkinson P, Hennekens CH \& Pollak M. Plasma insulin-like growth factor-I and prostate cancer risk: a prospective study. Science $1998279563-566$.

7 Renehan AG, Zwahlen M, Minder C, O'Dwyer ST, Shalet SM \& Egger M. Insulin-like growth factor (IGF)-I, IGF binding protein-3, and cancer risk: systematic review and meta-regression analysis. Lancet $20043631346-1353$.

8 Spallarossa P, Brunelli C, Minuto F, Caruso D, Battistini M, Caponnetto S \& Cordera R. Insulin-like growth factor-I and angiographically documented coronary artery disease. American Journal of Cardiology 199677 2000-2002.

9 Juul A, Scheike T, Davidsen M, Gyllenborg J \& Jorgensen T. Low serum insulin-like growth factor I is associated with increased risk of ischemic heart disease: a population-based case-control study. Circulation $2002106939-944$.

10 Sandhu MS, Heald AH, Gibson JM, Cruickshank JK, Dunger DB \& Wareham NJ. Circulating concentrations of insulin-like growth factor-I and development of glucose intolerance: a prospective observational study. Lancet 2002359 1740-1745.

11 Laughlin GA, Barrett-Connor E, Criqui MH \& Kritz-Silverstein D. The prospective association of serum insulin-like growth factor I (IGF-I) and IGF-binding protein-1 levels with all cause and cardiovascular disease mortality in older adults: the Rancho Bernardo Study. Journal of Clinical Endocrinology and Metabolism 200489 $114-120$.

12 Bayes-Genis A, Conover CA \& Schwartz RS. The insulin-like growth factor axis: a review of atherosclerosis and restenosis. Circulation Research 200086 125-130.

13 Ruotolo G, Bavenholm P, Brismar K, Efendic S, Ericsson CG, de Faire U, Nilsson J \& Hamsten A. Serum insulin-like growth factor-I level is independently associated with coronary artery disease progression in young male survivors of myocardial infarction: beneficial effects of bezafibrate treatment. Journal of the American College of Cardiology 200035 647-654.

14 Fischer F, Schulte H, Mohan S, Tataru MC, Kohler E, Assmann G \& von Eckardstein A. Associations of insulin-like growth factors, insulin-like growth factor binding proteins and acid-labile subunit with coronary heart disease. Clinical Endocrinology 200461 595-602.

15 Lieberman SA, Butterfield GE, Harrison D \& Hoffman AR. Anabolic effects of recombinant insulin-like growth factor-I in cachectic patients with the acquired immunodeficiency syndrome. Journal of Clinical Endocrinology and Metabolism 199478 404-410.

16 Gianotti L, Broglio F, Ramunni J, Lanfranco F, Gauna C, Benso A, Zanello M, Arvat E \& Ghigo E. The activity of GH/IGF-I axis in anorexia nervosa and in obesity: a comparison with normal subjects and patients with hypopituitarism or critical illness. Eating and Weight Disorders 19983 64-70.

17 Ponzer S, Tidermark J, Brismar K, Soderqvist A \& Cederholm T. Nutritional status, insulin-like growth factor-I and quality of life in elderly women with hip fractures. Clinical Nutrition 199918 241-246.

18 Lebl J, Zahradnikova M, Bartosova J, Zemkova D, Pechova M \& Vavrova V. Insulin-like growth factor-I and insulin-like growth factor-binding protein-3 in cystic fibrosis: a positive effect of antibiotic therapy and hyperalimentation. Acta Paediatrica 200190 $868-872$.

19 Veldhuis JD \& Iranmanesh A. Physiological regulation of the human growth hormone $(\mathrm{GH})$-insulin-like growth factor type I (IGF-I) axis: predominant impact of age, obesity, gonadal function, and sleep. Sleep 199619 (Suppl 10) S221-S224.

20 Marin P, Kvist H, Lindstedt G, Sjostrom L \& Bjorntorp P. Low concentrations of insulin-like growth factor-I in abdominal obesity. International Journal of Obesity Related Metabolic Disorders 1993 $1783-89$.

21 Maccario M, Grottoli S, Aimaretti G, Gianotti L, Endrio Oleandri S, Procopio M, Savio P, Tassone F, Ramunni J, Camanni F \& Ghigo E. IGF-I levels in different conditions of low somatotrope secretion in adulthood: obesity in comparison with GH deficiency. Panminerva Medicine 199840 98-102. 
22 Maccario M, Ramunni J, Oleandri SE, Procopio M, Grottoli S, Rossetto R, Savio P, Aimaretti G, Camanni F \& Ghigo E. Relationships between IGF-I and age, gender, body mass, fat distribution metabolic and hormonal variables in obese patients. International Journal of Obesity Related Metabolic Disorders 199923 612-618.

23 Rasmussen MH, Frystyk J. Andersen T, Breum L, Christiansen JS \& Hilsted J. The impact of obesity, fat distribution, and energy restriction on insulin-like growth factor-I (IGF-I), IGF-binding protein-3, insulin, and growth hormone. Metabolism $1994 \mathbf{4 3}$ 315-319.

24 Frystyk J, Skjaerbaek C, Vestbo E, Fisker S \& Orskov H. Circulating levels of free insulin-like growth factors in obese subjects: the impact of type 2 diabetes. Diabetes and Metabolism Research Reviews 199915 314-322.

25 Maccario M, Tassone F, Gauna C, Oleandri SE, Aimaretti G, Procopio M, Grottoli S, Pflaum CD, Strasburger CJ \& Ghigo E. Effects of short-term administration of low-dose rhGH on IGFlevels in obesity and Cushing's syndrome: indirect evaluation of sensitivity to GH. European Journal of Endocrinology $2001 \mathbf{1 4 4}$ 251-256.

26 Landin-Wilhelmsen K, Wilhelmsen L, Lappas G, Rosen T, Lindstedt G, Lundberg PA \& Bengtsson BA. Serum insulin-like growth factor I in a random population sample of men and women: relation to age, sex, smoking habits, coffee consumption and physical activity, blood pressure and concentrations of plasma lipids, fibrinogen, parathyroid hormone and osteocalcin. Clinical Endocrinology 199441 351-357.

27 Clasey JL, Weltman A, Patrie J, Weltman JY, Pezzoli S, Bouchard C, Thorner MO \& Hartman ML. Abdominal visceral fat and fasting insulin are important predictors of 24-hour GH release independent of age, gender, and other physiological factors. Journal of Clinical Endocrinology and Metabolism 200186 3845-3852.

28 Kunitomi M, Wada J, Takahashi K, Tsuchiyama Y, Mimura Y, Hida K, Miyatake N, Fujii M, Kira S, Shikata K \& Maknio H.
Relationship between reduced serum IGF-I levels and accumulation of visceral fat in Japanese men. International Journal of Obesity Related Metabolic Disorders 200226 361-369.

29 Brabant G, von zur Mühlen A, Wüster C, Ranke MB, Kratzsch J. Kiess W, Ketelslegers JM, Wilhelmsen L, Hulthen L, Saller B, Mattsson A, Wilde J, Schemer R \& Kann P and the German KIMS Board. Serum insulin-like growth factor I reference values for an automated chemiluminescence immunoassay system: results from a multicenter study. Hormone Research 200360 $53-60$.

30 Wittchen HU, Glaesmer H, März W, Stalla GK, Lehnert H, Zeiher AM, Silber S, Koch U, Böhler S Pittrow D \& Ruf G for the DETECT Study Group. Cardiovascular risk factors in primary care patients: methods and baseline prevalence results from the DETECT program. Current Medical Research and Opinion 2005 12 619-629.

31 Veldhuis JD, Iranmanesh A, Ho KK, Waters MJ, Johnson ML \& Lizarralde G. Dual defects in pulsatile growth hormone secretion and clearance subserve the hyposomatotropism of obesity in man. Journal of Clinical Endocrinology and Metabolism 1991 72 51-59.

32 Ashwell MA, Cole TJ \& Dixon AK. Ratio of waist circumference to height is strong predictor of intra-abdominal fat. British Medical Journal $1996313559-560$.

33 Svensson J. Johannsson G \& Bengtsson BA. Insulin-like growth factor-I in growth hormone-deficient adults: relationship to population-based normal values, body composition and insulin tolerance test. Clinical Endocrinology 199746 579-586.

Received 2 December 2005

Accepted 7 February 2006 